\title{
A Stator and Rotor Fault Detection Technique for Induction Machines in Traction Applications for Electric or Hybrid Electric Vehicles
}

\begin{abstract}
Christian Kral*, Hansjörg Kapeller*, Franz Pirker*
Three phase induction machines for traction applications in electric and hybrid electric vehicles can be used with a fixed gear due to the wide speed range enabled by field weakening. Although the induction machine is know as an extremely reliable and robust device, machine faults may occur. Machine faults which do not become detected may cause complete failure of the vehicle. Therefore, early detection of machine faults must be seen as important contribution for reliability and predictive maintenance. Stator winding and rotor failures, however, are a serious problem of squirrel cage induction machines. In an electric or a hybrid electric vehicle the traction machine may undergo severe thermal stress. Stator faults may occur much faster due to insulation breakdown or overload and are therefore more critical with respect to time. Such failures have therefore to be detected immediately after occurring. This paper presents fault detection techniques for stator and rotor faults of squirrel cage induction machines. Both the presented methods are model based techniques, competent to handle variable speed and load operating conditions.
\end{abstract}

Keywords: Induction Motor, Electric Drive, Maintenance

\section{INTRODUCTION}

Typical faults of induction machines have the following classification:

- Stator winding faults - electrical asymmetries of the stator winding, e.g. due to the voltage stress of the winding caused by fast switching inverters

- Rotor faults - cracks or broken bars due to thermal stress during starting, in particular at traction applications

- Bearings - Faulty or broken bearings due to aging and wearout

- Eccentricities and mechanical imbalances - Bent shaft or mechanical wearout of the bearings, defective mounting or fabrication of the rotor or shaft

Machine faults give rise to mechanical vibrations, acoustic noise, electromagnetic emission, torque oscillations, local temperature increase as well as current (and voltage) harmonic components. Depending on the fault type, some of these physical quantities may have a stronger fault signature, whereas other physical quantities show a weak fault signature. Generally speaking, machine faults due to electrical asymmetries, such as stator winding faults and rotor faults,

\footnotetext{
*Arsenal Research, Giefinggasse 2, 1210 Vienna, Austria, email: christian.kral@arsenal.ac.at; hansjoerg.kapeller@arsenal.ac.at; franz.pirker@arsenal.ac.at
}

give rise to dominant electrical signatures and electromagnetic emission which can be detected by techniques evaluating current, voltage and flux signals. Mechanical vibrations, acoustic noise and temperature increase are secondary effects and thus more difficult to detect. Mechanical faults such as bearing faults, eccentricities and mechanical imbalances are mechanical disturbances and result more significantly in a vibration signatures than in an electrical signature. This is due to the fact, that the origin of fault is mechanical. Therefore, the impact of the mechanical movement of the rotor on the air gap field, and, furthermore, on currents and voltages, is a secondary effect related with mechanical faults.

Several fault statistics with respect to the classified electrical asymmetries and mechanical faults have been presented $[1,2,3,4]$. It must, however, be noted, that the distribution of faults is highly dependent on the application it refers to. Most of the published statistics have been performed for industrial motors. For traction machines, which have certain overload capabilities, electrical asymmetries may be much more likely than for industrial applications due to the very high temperature rise at low ambient temperatures. The mechanical tensions due to the thermal stress may cause cracks in the junction of rotor bars and rotor end rings of the squirrel cage. A single broken rotor then leads to an increased current density and temperature of the adjacent bars. Due to this effects, a chain reaction can be caused which gives rise to several, side by side located broken rotor bars.

In an electric or hybrid electric vehicle the electric machine is supplied by a power source, which may be a battery, a super capacitor or a fuel cell. For controlling the electric machine, a power converter is required (Fig. 1). Flux and torque 
control of a modern drive is usually implemented on a digital signal processor (DSP). Such a DSP controlled power converter is usually equipped with current and often also with voltage sensors. An accurate torque controlled induction machine drive also requires a speed sensor or an encoder for working properly around stand still. These available sensors can also be used for implementing monitoring and fault diagnostic algorithms on the DSP.

\section{SPACE PHASORS AND SEQUENCE COMPONENTS}

From three measured phase voltages $v_{1}, v_{2}$ and $v_{3}$, and three measured phase currents $i_{1}, i_{2}$ and $i_{3}$ the stator (superscript s) voltage and the stator current space phasor can be computed.

$$
\begin{aligned}
\underline{V}_{s} & =\frac{2}{3}\left(v_{1}+e^{\mathrm{j} 2 \pi / 3} v_{2}+e^{-\mathrm{j} 2 \pi / 3} v_{3}\right) \\
\underline{I}_{s} & =\frac{2}{3}\left(i_{1}+e^{\mathrm{j} 2 \pi / 3} i_{2}+e^{-\mathrm{j} 2 \pi / 3} i_{3}\right)
\end{aligned}
$$

In this equation $\mathrm{j}$ is the imaginary unit. The space phasors can be computed independently of the waveform of the three voltages or currents. Space phasor theory is therefore neither restricted to sinusoidal nor periodic signals [5].

In a DSP, the space phasors can be computed instantaneously, evaluating the sampled voltages $v_{1, k}, v_{2, k}$ and $v_{3, k}$ and the sampled currents $i_{1, k}, i_{2, k}$ and $i_{3, k}$, where $k$ is the index number. A fast Fourier transform (FFT) can be applied to the sampled voltage and current space phasors $\underline{V}_{s, k}$ and $\underline{I}_{s, k}$ over one full time period $T$. The positive (index $p$ ) and the negative (index $n$ ) sequence components of the stator voltage and current can then be computed according to:

$$
\begin{aligned}
\underline{V}_{s p} & =\frac{1}{N} \sum_{k=0}^{N-1} \underline{v}_{s, k} e^{-\mathrm{j} 2 \pi k / N} \\
\underline{I}_{s p} & =\frac{1}{N} \sum_{k=0}^{N-1} \underline{i}_{s, k} e^{-\mathrm{j} 2 \pi k / N} \\
\underline{V}_{s n} & =\frac{1}{N} \sum_{k=0}^{N-1} \underline{v}_{s, k} e^{+\mathrm{j} 2 \pi k / N} \\
\underline{I}_{s n} & =\frac{1}{N} \sum_{k=0}^{N-1} \underline{i}_{s, k} e^{+\mathrm{j} 2 \pi k / N}
\end{aligned}
$$

The time period has to be determined from the actual stator supply frequency $f_{s}=\frac{1}{T}$. If the signal period $T$ is not an integer multiple of the sampling period $\Delta T$, linear interpolation can be used to "re-sample" the original signal such way, that the sampling period $\Delta T^{\prime}$ of the re-sampled signal fulfills the condition

$$
T=N \Delta T^{\prime} .
$$

For a three phase induction machine, the relationship between the voltages and currents of the positive and negative sequence components is:

$$
\left\lceil\begin{array}{l}
\underline{V}_{s p} \\
\underline{V}_{s n}
\end{array}\right\rceil=\left\lceil\left[\begin{array}{ll}
\underline{Z}_{s p p} & \underline{Z}_{s p n} \\
\underline{\underline{Z}}_{s n p} & \underline{\underline{Z}}_{s n n}
\end{array}\right\rceil\left\lceil\begin{array}{l}
\underline{I}_{s p} \\
\underline{I}_{s n}
\end{array}\right\rceil\right.
$$

In this equation the zero sequence component equation is not considered. The diagonal elements of the square matrix are the self impedances of the positive sequence, $\underline{Z}_{s p p}$, and the negative sequence, $\underline{Z}_{s n n}$. The off-diagonal elements $\underline{Z}_{s p n}$ and $\underline{Z}_{s n p}$ are the mutual impedances. These two terms are usually considered to be equal

$$
\underline{Z}_{s p n}=\underline{Z}_{s n p}
$$

For a perfectly symmetric machine these two terms are even zero. An inherent winding asymmetry or imperfection may result in non-zero values, however. For the stator fault detection technique proposed in this paper, these terms are not considered.

\section{STATOR WINDING FAULTS}

From an ideally symmetric induction machine with perfectly balanced voltage supply symmetrical currents arise. In this case, only a forward rotating voltage space phasors occurs. Therefore, the current space phasor also consists of a forward rotating space phasor, only. This means, that only positive sequence components (3) arise, whereas the negative sequence components (5) vanish. For mains supplied induction machines, a supply imbalance results in a negative sequence voltage component. This means that the voltage space phasor also consists of a backward rotating component. This voltage components causes a negative sequence current component due to the negative sequence impedance of the (symmetric) induction machine [6].

Symmetric supply voltage conditions and an electric asymmetry of the stator winding due to a stator winding fault give also rise to a negative sequence current. This is due to asymmetry of the winding which causes a backward rotating fundamental wave of the magnetic field in the air gap. From a negative sequence current component only it can therefore not be deduced whether the induction machine or the voltage supply is asymmetric.

For an uncontrolled induction machine drive it can be assumed that the voltage supply is symmetric. In this case, a negative sequence component of the current clearly indicates a stator winding asymmetry or fault. For traction and other higher sophisticated drive applications, the drive is usually controlled. The control technique, however, may be controlling the currents in such way that mostly a positive sequence current component occurs. Then it may be the case that a machine imbalance gets also reflected in a negative sequence of the voltages.

Stator winding faults can be classified the following way [7]:

- Electric stress due to the fast switching semiconductors of modern power inverters [8]

- Thermal stress caused by thermal aging of the insulation and overloading

- Mechanical stress due to coil movement and the rotor rubbing the stator

- Environmental stress and contamination 


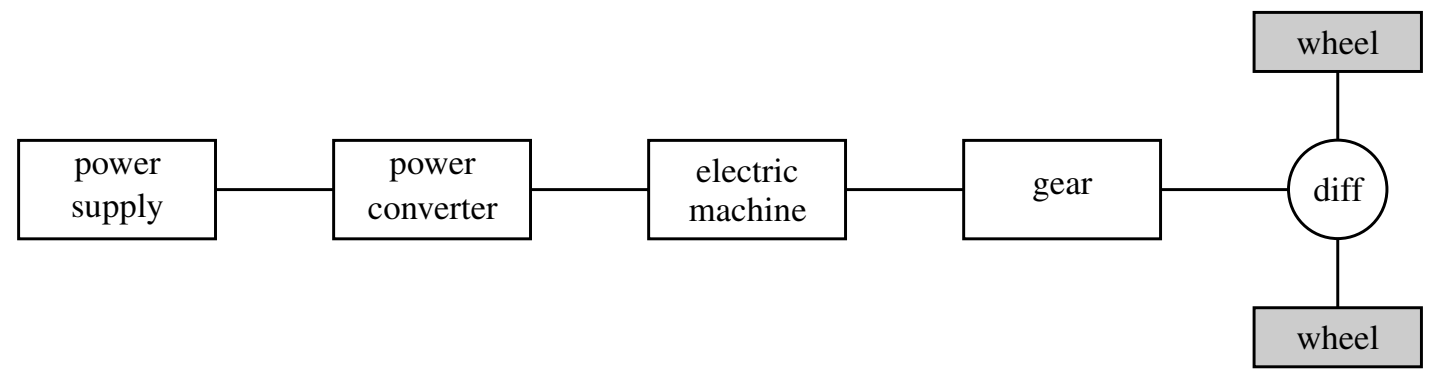

Fig. 1: Scheme of an electric or a hybrid electric vehicle

\subsection{Known Stator Winding Fault Detection Techniques} One difficulty in detecting stator winding faults is that inherent machine and instrumentation imbalances also affect the (measured) negative sequence voltage or current. Several technique have been published that propose techniques for minimizing these effects. These strategies incorporate approaches such as coupled circuit models [9] which consider the so called residual current sources and neural networks [10]. All the stator fault detection methods published in $[9,10,11,12,13,14]$ attempt to detect a change in the unbalance in the electric machine by analyzing the stator current.

For the detection of stator winding faults, search coils can be embedded in the stator slots [15]. For this technique, usually two or more search coils with either equal or different coil pitch are connected in series. Due to the sophisticated series connection undesired harmonics effects are compensated and the wanted signal can be extracted. Since this technique evaluates the effect of magnetic field in the air gap, stator winding faults and supply imbalances cannot be distinguished.

A second technique based on electromagnetic emission for the stator winding fault detection uses stray flux sensors. The stray flux emitted by the induction machine induces a voltage in the stray flux sensor that is analyzed by signal processing technique [16]. Such techniques are therefore designated as flux signal analysis (FSA).

Model based techniques can be used to compare a modeled and a measured quantity. In [17] a technique is presented that compares the measured stator current space phasor with a quantity, modeled by a current model. The locus of the deviation of the modeled and measured current space phasor clearly indicates short circuits in phase windings and open phase windings.

In [18] a technique is presented, that evaluates the transient electrical current response of inverter fed induction machines. The proposed method uses the reaction of the machine to a transient excitation caused by the switching of the inverter. This transient excitation may be realized by separate voltage test pulses or may be integrated into the pulse width modulation (PWM) scheme of the inverter.

\subsection{Proposed Stator Winding Fault Detection Tech- nique}

The stator fault detection method proposed in this paper relies on the comparison of measured negative sequence impedance of the machine with a modeled one as shown in

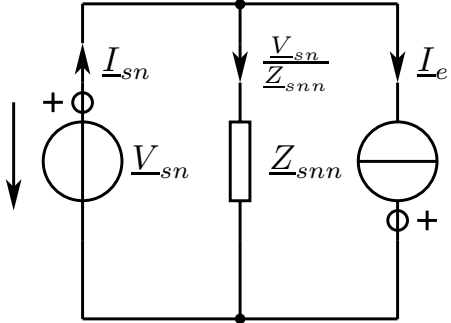

Fig. 2: Equivalent circuit for detecting stator turn faults

Fig. 2. In this equivalent circuit, the voltage source applies the negative sequence voltage $\underline{V}_{s n}$ to the circuit. The negative sequence self impedance $\underline{Z}_{s n n}$ is somehow identified from the real machine. The identification can either rely on a calculation as stated in [19], or on a measurement with a selectively injected negative sequence voltage. The current source $\underline{I}_{e}$ in the equivalent circuit therefore represents deviation of the modeled current $\frac{\underline{V}_{s n}}{\underline{Z}_{s n n}}$ and the measured negative sequence current $\underline{I}_{s n}$. The current $\underline{I}_{e}$ is therefore also designated as error current.

A measurement result of the magnitude of the error current of an $18.5 \mathrm{~kW}$ four pole induction machine is depicted in Fig. 3. The rated phase current of the machine is $18.9 \mathrm{~A}$. The asymmetric case refers to a winding arrangement where one group of turns is excluded from the series connection of a phase. According to Fig. 3, the magnitude of the error current, clearly indicates the machine winding asymmetry, independent of mechanical load. Additional measurement results are presented in [19].

\section{ROTOR FAULT DETECTION}

An ideally symmetric induction machine has constant electric torque and sinusoidal currents. An electric rotor asymmetry disturbs the current distribution in the rotor cage which gives rise to additional harmonics effects in the air gap field. The reaction of this disturbance on the torque are a double slip frequency oscillation superimposed to the average load torque, and, for a voltage supplied induction machine, side band currents in the stator current spectrum.

\subsection{Known Rotor Fault Detection Techniques}

Most rotor fault detection techniques are based on the so called current signature analysis (CSA). These techniques 


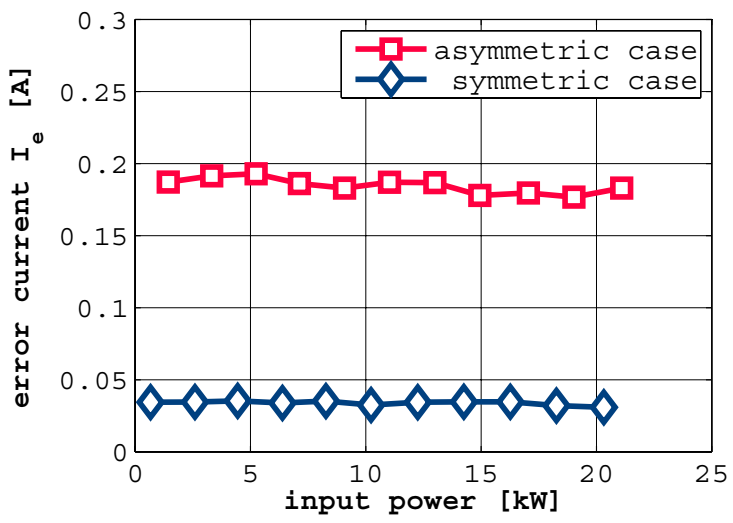

(a) Balanced supply voltage

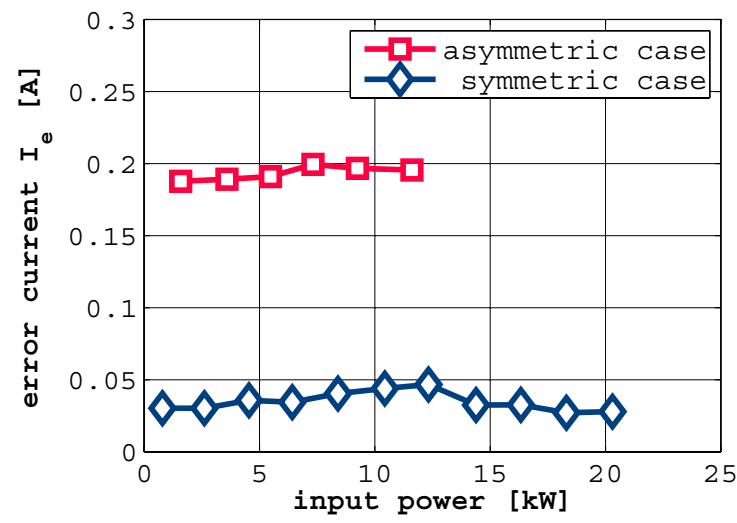

(b) Voltage asymmetry

Fig. 3: Magnitude of error current for symmetric machine and winding asymmetry

use a current sensor and signal processing techniques to identify and sometimes assess a rotor fault. The (first order) frequencies of the rotor fault specific stator current side bands in the harmonic spectrum are

$$
f_{i}=f_{s}(1 \pm 2 s) .
$$

These frequencies and the magnitudes of the respective components are dependent on the slip, $s$, and the stator supply frequency, $f_{s}$. The lower side band harmonic is dominant for high inertia drives, whereas low inertia drives show a more significant upper side band harmonic [20]. The magnitudes of the side band harmonics are strongly load dependent, which is a physical phenomenon. If an induction machine is operated at no load, rotor currents almost vanish. Therefore, the reactions of a rotor fault on the air gap field and the stator currents disappear, too.

In stead of current, electric power can be used to detect rotor faults [21, 22]. From the measured phase voltages and currents instantaneous power can be calculated:

$$
p=v_{1} i_{1}+v_{2} i_{2}+v_{3} i_{3}
$$

Due to the interaction of the rotor fault specific stator current harmonics with the fundamental of the supply voltage, (first order) fault specific power harmonics arise at double slip frequency,

$$
f_{p}=2 s f_{s} \text {. }
$$

This frequency component is also present in the electromagnetic torque of the induction machine.

\subsection{Proposed Rotor Fault Detection Technique}

The proposed method for detecting rotor faults is based on on-line machine models. These models are used for advanced machine control purpose [23]. The proposed method is introduced to the scientific community as Vienna Monitoring Method. It utilizes a voltage and a current model structure as shown as in Fig. 4. Both models calculate the flux space phasor and machine torque. In the case of an ideal symmetric machine, both models will calculate the same load torque value. In this case the torque deviation equals zero.

In case of an electric rotor asymmetry the different model structure and the different input quantities, cause the two machine models to respond differently. The electric asymmetry

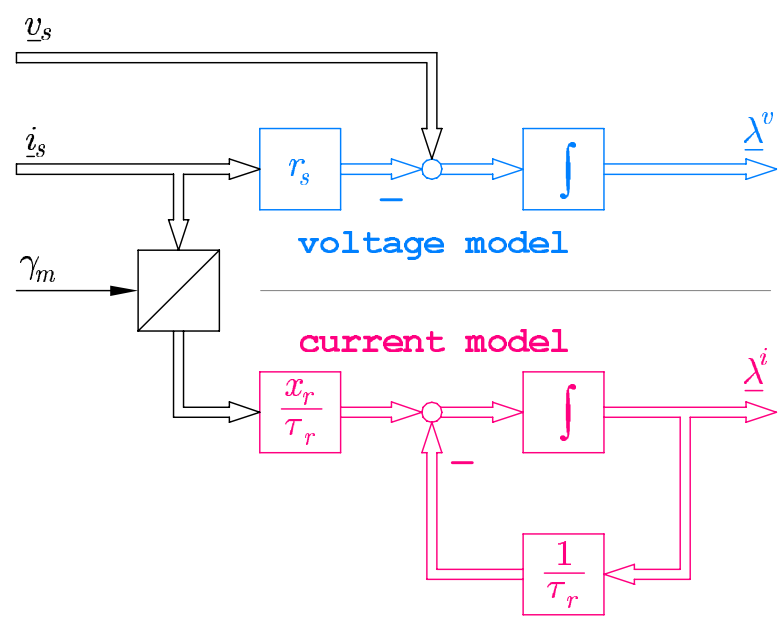

Fig. 4: Scheme of the voltage and the current model of the rotor monitoring method for detecting rotor faults

gives rise to double slip frequency torque oscillations in both models. The magnitude and phase shift of both torque signals is different, however. The torque deviation shows in this case, therefore, a double slip frequency oscillation, too. The magnitude of this torque deviation is linearly proportional to the load torque [24]. If the torque deviation is divided by the averaged load torque, the magnitude of the resulting signal is independent of load. In an actual application, however, a sophisticated spatial data clustering technique is used to eliminate the slip dependence of the time domain signal. The data clustering technique also averages the obtained data and leads therefore to a robust fault indicator $F$. Additional details about the Vienna Monitoring Method can be found in [25, 26, 27].

Measurement results for an $18.5 \mathrm{~kW}$ four pole induction machine with symmetric rotor cage and three broken rotor bars are compared in Fig. 5. For variable speed drive it is demonstrated in [28] that the fault indicator is independent of speed. Transient applications of the Vienna Monitoring are investigated in [29]. 


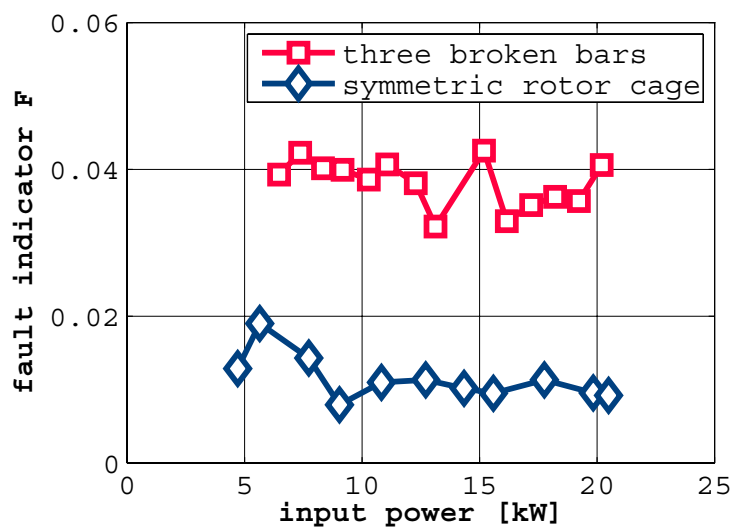

Fig. 5: Fault indicator for three broken bars and a symmetric rotor cage

\section{CONCLUSIONS}

For induction machines in electric and hybrid electric vehicles, typical machine faults are presented and discussed. For electrical asymmetries, a stator and a rotor fault detection technique are presented. The stator fault detection techniques is based on the evaluation of the negative sequence components of the measured voltages and currents. The presented rotor fault detection technique is the Vienna Monitoring Method which is based on the comparison of the calculated torque of two space phasor models. From the deviation of the torque that both models determine, a fault indicator can be obtained. Measurement results are presented that prove the applicability of both the proposed fault detection techniques.

\section{REFERENCES}

[1] W. Thomson, "A review of on-line condition monitoring techniques for three-phase squirrel-cage induction motors-past present and future," Conference Proceedings of the International Symposium on Diagnostics for Electrical Machines, Power Electronics and Drives, SDEMPED, pp. 3-18, 1999.

[2] I. M. R. W. Group, "Report of large motor reliability survey of industrial commercial installations," IEEE Transactions of Industry Applications, part I and II, vol. 1A-21, no. 4, pp. 853872, 1985.

[3] S. Nandi and H. Toliyat, "Condition monitoring and fault diagnosis of electrical machines-a review," Thirty-Fourth IAS Annual Meeting. Conference Record of the 1999 IEEE Industry Applications Conference, vol. 1, pp. 197-204, 1999.

[4] A. Wallace, A. von Jouanne, E. Wiedenbrug, J. Douglass, C. Wohlgemuth, and G. Wainwright, "A laboratory assessment of in-service motor efficiency testing methods," 1997. IEEE International Electric Machines and Drives Conference Record, 1997.

[5] P. Kovacs, Transient Phenomena in Electrical Machines. Budapest: Akademiai Kiado Verlag, 1984.

[6] S. B. Lee, R. Tallam, and T. Habetler, "A robust, on-line turn-fault detection technique for induction machines based on monitoring the sequence component impedance matrix," Issue: 3 Power Electronics, IEEE Transactions on , Volume: 18, pp. 865-872, May 2003.
[7] A. Siddique, G. Yadava, and B. Singh, "A review of stator fault monitoring techniques of induction motors," IEEE Transactions on Energy Conversion, vol. 20, pp. 106-114, Mar 2005.

[8] S. Campbell and G. Stone, "Examples of stator winding partial discharge due to inverter drives," Conference Record of the 2000 IEEE International Sympoium on Electrical Inulation, pp. 231-234, 2000.

[9] G. Kliman, W. Premerlani, R. Koegel, and D. Hoeweler, "A new approach to on-line turn fault detection in AC motors," Conference Proceedings of the IEEE Industry Application Society Annual Meeting, pp. 687-693, 1996.

[10] R. Tallam, T. Habetler, R. Harley, D. Gritter, and B. Burton, "Neural network based on-line stator winding turn fault detection for induction motors," Conference Record of the IEEE Industry Application Conference, IAS, 2000.

[11] J. Kohler, J. Sottile, and F. Trutt, "Alternatives for assessing the electrical integrity of induction motors," Conference Record of the 1989 IEEE Industry Applications Society Annual Meeting, 1989., pp. 1580-1586, 1989.

[12] S. Cruz and A. M. Cardoso, "Stator winding fault diagnosis in three-phase synchronous and asynchronous motors, by the extended park's vector approach," Conference Record of the IEEE Industry Application Conference, IAS, 2000.

[13] J. Sottile, F. Trutt, and J. Kohler, "Experimental investigation of on-line methods for incipient fault detection," Conference Record of the IEEE Industry Application Conference, IAS, 2000.

[14] M. Cash, T. Habetler, and G. Kliman, "Insulation failure prediction in induction machines using line-neutral voltages," Conference Proceedings of the IEEE Industry Application Society Annual Meeting, pp. 208-213, 1997.

[15] J. Fruechtenicht, "Diagnosesystem fuer DrehstromAsynchronmaschinen," etz-Archiv, vol. 11, pp. 145-153, 1989.

[16] H. Henao, C. Demian, and G.-A. Capolino, "A frequencydomain detection of stator winding faults in induction machines using an external flux sensor," Issue: 5 Industry Applications, IEEE Transactions on, Volume: 39, pp. 1272-1279, 2003.

[17] T. Wolbank and R. Wohrnschimmel, "On-line stator winding faults detection in inverter fed induction motors by stator current reconstruction," 468) Electrical Machine and Drive. Ninth International Conference on (Conf. Publ. No, pp. 253257, 1999.

[18] T. Wolbank and R. Wöhrnschimmel, "Transient electrical current response evaluation in order to detect stator winding interturn faults of invertor fed ac drives," IEEE, International Symposium on Diagnostics for Electrical Machines, Power Electronics and Drives, pp. 549-554, 2001.

[19] H. Kapeller, C. Kral, F. Pirker, and G. Pascoli, "Stator winding turn fault detection for induction machines," 5th IEEE International Symposium on Diagnostics for Electric Machines, Power Electronics and Drives, SDEMPED, 2005.

[20] C. Kral, F. Pirker, and G. Pascoli, "Influence of inertia on general effects of faulty rotor bars and the Vienna Monitoring Method," Conference Proceedings of the IEEE International Symposium on Diagnostics of Electrical Machines, Power Electronics and Drives, SDEMPED, pp. 447-452, 2001.

[21] S. Legowski, A. S. Ula, and A. Trzynadlowski, "Instantaneous power as a medium for the signature analysis of induction motors," IEEE Transactions on Industry Applications, vol. 32, no. 4, pp. 904-909, 1996. 
[22] A. Trzynadlowski and E. Ritchie, "Comparative investigation of diagnostic media for induction motors: a case of rotor cage faults," IEEE Transactions on Industrial Electronics, vol. 47, no. 5, pp. 1092-1099, 2000.

[23] R. Wieser, Modellierung umrichtergespeister Asynchronmaschinen zur Berechnung des Drehmoments. $\mathrm{PhD}$ thesis, TU Wien, 1996.

[24] R. Wieser, C. Kral, F. Pirker, and M. Schagginger, "On-line rotor cage monitoring of inverter-fed induction machines by means of an improved method," IEEE Transactions on Power Electronics, vol. 14, pp. 858-865, September 1999.

[25] C. Kral, F. Pirker, and G. Pascoli, "Influence of load torque on rotor asymmetry effects in squirrel cage induction machines including detection by means of the Vienna Monitoring Method," Conference Proceedings EPE, 2001.

[26] C. Kral, F. Pirker, G. Pascoli, and H. Oberguggenberger, "Influence of rotor cage design on rotor fault detection by means of the Vienna Monitoring Method," International Conference on Electric Machines, ICEM, 2002.

[27] C. Kral, H. Kapeller, F. Pirker, and G. Pascoli, "Discrimination of rotor faults and low frequency load torque modulations of squirrel cage induction machines by means of the vienna monitoring method," 36th IEEE Power Electronics Specialists Conference, 2005.

[28] C. Kral, F. Pirker, and G. Pascoli, "Detection of rotor faults in inverter fed induction machines by means of the Vienna Monitoring Method-a proposed application for traction drives," Conferences Proceedings of the first International Conference on Railway Traction Systems, RTS, vol. 3, pp. 79-89, 2001.

[29] C. Kral, H. Kapeller, F. Pirker, and G. Pascoli, "Detection of rotor faults under transient operating conditions by means of the vienna monitoring method," 5th IEEE International Symposium on Diagnostics for Electric Machines, Power Electronics and Drives, SDEMPED, 2005.

\section{BIOGRAPHIES}

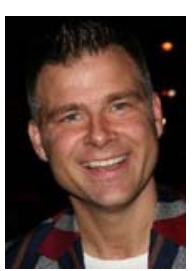

Christian Kral received the Dipl.-Ing. and Ph.D. degrees from the Vienna University of Technology, Vienna, Austria, in 1997 and 1999, respectively. From 1997 to 2000, he was a Scientific Assistant at the Institute of Electrical Drives and Machines, Vienna University of Technology. Since 2001, he has been with Arsenal Research (Österreichisches Forschungs- und Prüfzentrum Arsenal Ges.m.b.H.), Vienna, Austria. From January 2002 until April 2003 he was on sabbatical as a Visiting Professor at the Georgia Institute of Technology, Atlanta. His research activities are focused on diagnostics and monitoring techniques, machine models, and the simulation of faulty machine behavior. Christian Kral is IEEE Senior Member as well as member of the Austrian Electrotechnical Association OVE and the Modelica Association.

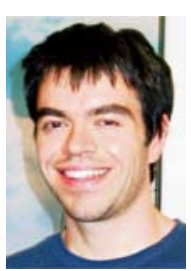

Hansjörg Kapeller was born in 1978 in Italy. He received the Dipl.-Ing. degree in electrical engineering from Vienna University of Technology, Vienna, Austria, in 2004. Since October 2004, he has been an engineer of the business unit Monitoring, Energy and Drive Technologies with Arsenal Research, Vienna, Austria. His main research interests are monitoring of faulty induction machines, simulation and control of electric drives.

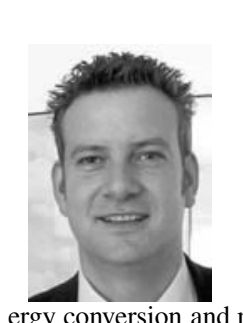

Franz Pirker was born in 1968. He received the Dipl.-Ing. degree in electrical engineering from Vienna University of Technology, Vienna, Austria, in 1997. Since 1999, he has been the head of the business unit Monitoring, Energy and Drive Technologies, arsenal research (Österreichisches Forschungsund Prüfzentrum Arsenal Ges.m.b.H.), Vienna, Austria. In this area, the main research topics are alternative drive concepts like hybrid electric vehicles, energy conversion and monitoring of electrical drives and machines. 